\title{
ANÁLISE TEXTUAL DISCURSIVA NA PESQUISA SOBRE FORMAÇÃO DE PROFESSORES DE MATEMÁTICA
}

\section{DISCURSIVE TEXTUAL ANALYSIS IN RESEARCH ON MATHEMATICS TEACHER TRAINING}

\author{
Liliane Silva de Antiqueira ${ }^{1}$ \\ Celiane Costa Machado ${ }^{2}$
}

\begin{abstract}
Resumo: O artigo tem como objetivo apresentar o percurso da Análise Textual Discursiva em uma pesquisa qualitativa desenvolvida no âmbito da formação de professores de Matemática, bem como explicitar algumas aprendizagens possibilitadas ao pesquisador por essa metodologia. Para isso, são expostos alguns princípios que orientaram a realização da pesquisa qualitativa, e é descrito, de modo gradual, como foi o processo de desenvolvimento da Análise Textual Discursiva nessa pesquisa. Ademais, é exibido o recorte de um dos metatextos produzidos na tese, visando a explicitar o exercício de diálogo intenso estabelecido com os interlocutores empíricos e teóricos, assim como a expressão dos argumentos necessários para comunicar as compreensões emergentes em uma pesquisa qualitativa. Logo, o modo como essa metodologia possibilita conduzir o pesquisar faz com que o pesquisador se sinta desafiado a ler e escrever sempre mais e, principalmente, a aprender.
\end{abstract}

Palavras-chave: Pesquisa Qualitativa; Análise Textual Discursiva; Formação de professores de Matemática.

\begin{abstract}
The article aims to present the path of Textual Discursive Analysis in a doctoral research that was carried out in the context of the formation of mathematics teachers, as well as to explain some learning made possible by this methodology to the researcher. For that, some principles are exposed that guided the accomplishment of the qualitative research and described, gradually, how was the development process of the Discursive Textual Analysis in this research. In addition, an excerpt from one of the metatexts produced in the thesis is shown, aiming to show the exercise of the intense dialogue established with the empirical and theoretical interlocutors, as well as the expression of the arguments that are necessary to communicate the emerging understandings in a qualitative research. Therefore, the way in which this methodology makes it possible to conduct research makes the researcher feel challenged to read and write more and more, and especially to learn.
\end{abstract}

Keywords: Qualitative Research; Discursive Textual Analysis; Teacher Training.

\section{Introdução}

O artigo é resultado de uma pesquisa qualitativa de doutorado (ANTIQUEIRA, 2018) que utilizou a Análise Textual Discursiva (ATD), conforme Moraes e Galiazzi (2011), como referencial para análise do material empírico da pesquisa e para fundamentação teórica sobre a linguagem escrita. Essa metodologia de análise origina-se

\footnotetext{
${ }^{1}$ Doutora em Educação em Ciências pela Universidade Federal do Rio Grande (FURG). Instituto Federal do Rio Grande do Sul (IFRS), Rio Grande, Rio Grande do Sul, Brasil. E-mail: lilianeantiqueira@gmail.com

${ }^{2}$ Doutora em Matemática Aplicada pela Universidade Federal do Rio Grande do Sul (UFRGS). Universidade Federal do Rio Grande (FURG), Rio Grande, Rio Grande do Sul, Brasil. E-mail: celianecmachado@gmail.com
} 
do encontro com a fenomenologia de Husserl e de Merleau-Ponty com a pesquisa naturalística, com o existencialismo e com a hermenêutica existencial de Heidegger. Além disso, tem sido utilizada em pesquisas de diferentes áreas, como Comunicação, Psicologia, Educação, Serviço Social e Educação Ambiental (MORAES, 1991, 2003).

Na ATD, são realizados movimentos de desconstrução, seguidos de reconstrução de um conjunto de materiais linguísticos e discursivos, o que possibilita ao pesquisador aprofundar a compreensão do fenômeno e do discurso investigados. Assim, a pesquisa qualitativa à qual se refere este artigo apresentou compreensões dos sentidos construídos pelos professores de Matemática em formação acadêmico-profissional ${ }^{3}$ em relação ao aprender com e sobre a linguagem escrita praticada no espaço formativo do Programa Institucional de Bolsa de Iniciação à Docência $\left(\right.$ PIBID $\left.^{4}\right)$ da Universidade Federal do Rio Grande (FURG). O espaço da investigação-formação ${ }^{5}$ foi o subprojeto Matemática, e o grupo de sujeitos constituiu-se de 11 licenciandos em Matemática e professores supervisores.

Como procedimento metodológico, a ATD foi utilizada para examinar as informações discursivas ${ }^{6}$ produzidas na pesquisa qualitativa realizada. Tal opção foi a melhor, em face de uma das possibilidades que a ATD oferece: a de produzir novas compreensões a partir do que foi escrito, contado e conversado, estando esses elementos entrelaçados em todos os momentos da pesquisa. Além disso, escolheu-se o processo emergente, ou seja, pretendeu-se construir categorias a partir das informações analisadas, sem adotar categorias a priori.

As informações discursivas produzidas originaram-se de duas etapas. A primeira foi a proposta denominada de "Movimentando-se com a Escrita" (ANTIQUEIRA; MACHADO, 2017a), desenvolvida com os sujeitos nas rodas de formação do subprojeto Matemática, culminando com produção de narrativas, depoimentos escritos, planejamentos de aula, relatórios, histórias em quadrinhos e relatos da prática. A segunda etapa foi a realização de uma entrevista/conversa, sem seguir um questionário pré-

\footnotetext{
${ }^{3} \mathrm{O}$ termo formação acadêmico-profissional fundamenta-se na ideia de formação pensada como um processo inacabado que se dá em um continuum, compartilhada por Tardif (2014) e Diniz-Pereira (2008). ${ }^{4}$ Política de formação que possibilita melhorar a qualidade da educação básica e inserir alunos dos cursos de licenciatura no ambiente escolar, promovendo ações e intenso diálogo entre a Instituição de Ensino Superior e as escolas da rede pública (BRASIL, 2013).

${ }^{5}$ Atribuiu-se essa denominação por entender-se que o subprojeto Matemática foi o espaço de investigação da pesquisadora e também o espaço de formação de todos os envolvidos na pesquisa. Refere-se ao ambiente natural em que os sujeitos da pesquisa estão inseridos.

${ }^{6}$ Entende-se, por informações discursivas, o conjunto de produções textuais que constitui o corpus de uma pesquisa (MORAES; GALIAZZI, 2011).
} 
elaborado, pois, neste caso, "o pesquisador estaria direcionando o dito pelo entrevistado e partindo de a prioris", como menciona Bicudo (2020, p. 53). A entrevista aconteceu ao modo de um diálogo, em que a pesquisadora ficou atenta ao dito, ouvindo o exposto. Nesse ouvir, algumas pequenas intervenções puderam ocorrer, cujo sentido se fez na realidade então vivenciada, tanto pela pesquisadora, quanto pelos sujeitos (BICUDO, 2020). Os diálogos foram gravados e transcritos, resultando na produção de materiais textuais.

Diante do que foi feito, o corpus da pesquisa consistiu em um amplo conjunto de produções textuais, composto por escritas de narrativas, depoimentos escritos, planejamento de aula, produção de hisórias em quadrinho e escrita de relatórios. Porém, devido à sua amplitude, foi necessário fazer uma seleção e delimitação, pois, de acordo com Moraes e Galiazzi (2011, p. 16), "seguidamente não trabalhamos com todo o 'corpus"”.

Em suma, os objetivos do artigo são apresentar o percurso da ATD na pesquisa qualitativa de Antiqueira (2018), feita no âmbito da formação de professores de Matemática, e explicitar algumas aprendizagens possibilitadas à pesquisadora por essa metodologia na referida pesquisa. Para isso, além desta introdução, apresenta-se o primeiro tópico, composto por alguns princípios que orientaram a pesquisa qualitativa. No segundo, é abordado o processo de desenvolvimento da ATD na pesquisa realizada. O terceiro exibe o recorte de um dos metatextos produzidos. No quarto tópico, são apresentadas algumas aprendizagens possibilitadas por essa metodologia ao pesquisador. Ao término do texto, são feitas as considerações finais.

\section{Princípios que orientaram a pesquisa qualitativa}

O que é pesquisar? Segundo Bicudo (2005, p. 8), pesquisar "é ter uma interrogação e andar em torno dela, em todos os sentidos, sempre buscando suas múltiplas dimensões e andar outra vez e outra ainda, buscando mais sentido, mais dimensões, e outra vez mais". Partindo dessa definição, pensar o percurso de uma pesquisa remete-nos a um caminho com mais incertezas do que certezas, com mais interrogações do que respostas.

Nas palavras de Garcia (2001, p.16), o pesquisar e o aprender estão intrinsecamente associados, pois "hoje sei que a dúvida, a incerteza, a insegurança, a consciência de meu ainda não saber é o que me convida a investigar e, investigando, sei 
que posso aprender algo que antes não sabia". Na pesquisa qualitativa, o pesquisador deve estar aberto ao desconhecido; os resultados não são previsíveis - e nem poderiam ser, na medida em que se buscam o conhecimento emergente e novas aprendizagens. Logo, não se deve ter a pretensão de encontrar verdades definitivas.

Marques (2011) corrobora essa ideia ao destacar que, na pesquisa, como em toda obra de arte, a segurança se produz na incerteza dos caminhos. Ao encontro disso, Bicudo (2012) salienta que não há um modo certo de pesquisar, não há um padrão de procedimentos a serem seguidos para garantir que a investigação seja bem-sucedida, e o que se tem são interrogações. São essas interrogações que orientam para onde o olhar do pesquisador deve dirigir-se e em quais perspectivas e modos deapresentação do fenômeno ele deve focar.

No caso da pesquisa qualitativa, esta utiliza mecanismos que intencionam criar informações descritivas, permitindo que o pesquisador observe a forma de pensar dos sujeitos e, assim, compreenda o fenômeno (MORAES; GALIAZZI, 2011; STAKE, 2011; BOGDAN; BIKLEN, 1994). Para Bicudo (2012, p. 3), a pesquisa qualitativa é "um modo de proceder que permite colocar em relevo o sujeito do processo, não olhado de modo isolado, mas contextualizado social e culturalmente".

Entende-se que o espaço de investigação-formação da pesquisa qualitativa precisa ser constituído por uma realidade em movimento, em que os sujeitos devem ser compreendidos em seu processo de transformação e mudança, portanto, em seu aspecto histórico. Isso porque "[...] não se cria artificialmente uma situação para ser pesquisada, mas se vai ao encontro da situação no seu acontecer, no seu processo de desenvolvimento" (FREITAS, 2002, p. 27).

Desse modo, a pesquisa qualitativa em uma abordagem histórico-cultural, no âmbito das Ciências Humanas, busca mostrar o sujeito em sua totalidade, considerando sua relação com a sociedade à qual pertence. Sobre essa abordagem, destaca-se que enfatiza a compreensão dos fenômenos a partir de seu acontecer histórico no
qual o particular é considerado uma instância da totalidade social. A pesquisa
é vista como uma relação entre sujeitos, portanto, dialógica, na qual o
pesquisador é uma parte integrante do processo investigativo. Essas ideias têm
implicações nas características processuais e éticas do fazer pesquisa em
Ciências Humanas que se refletem na relação pesquisador-pesquisado, nos
próprios instrumentos utilizados e na análise de dados (FREITAS, 2002, p. 21).

Uma das implicações às quais a autora se refere, com reflexo direto na relação pesquisador-pesquisado, diz respeito ao objeto de estudo nas Ciências Humanas, isto é, o homem. Diante desse ser que expressa suas ideias, “o pesquisador não pode se limitar ao 
ato contemplativo, pois encontra-se perante um sujeito que tem voz, e não pode apenas contemplá-lo, mas tem de falar com ele, estabelecer um diálogo com ele" (FREITAS, 2002, p.24). A relação entre sujeitos em uma perspectiva dialógica é uma atitude balizadora da pesquisa qualitativa com o olhar na abordagem histórico-cultural.

Em diálogo com Stake (2011, p.42) sobre a essência da abordagem qualitativa, o autor acrescenta que compreender um fenômeno "exige uma ampla mudança de contextos: temporal e espacial, histórica, política, econômica, cultural, social, pessoal". Ainda, o autor considera que a pesquisa qualitativa se baseia na percepção e na compreensão humanas; como tal, pode ser pensada a partir de quatro características: interpretativa, experiencial, situacional e humanística.

A primeira delas permite-nos entender que o estudo qualitativo se centra nos significados das relações humanas a partir de diferentes pontos de vistas e que as descobertas são frutos de interações entre pesquisador e sujeitos (STAKE, 2011). O que o pesquisador seleciona para "ver" depende muito de sua história pessoal, de sua vivência e das leituras que faz. São vários olhares de compreensões e interpretações de um mesmo fenômeno. Ao encontro disso, está o pensamento de Freitas (2002, p. 29), ao revelar que “a contextualização do pesquisador é também relevante: ele não é um ser humano genérico, mas um ser social, faz parte da investigação e leva para ela tudo aquilo que o constitui como um ser concreto em diálogo com o mundo em que vive”.

A segunda característica denota que o estudo qualitativo é empírico e está direcionado ao campo. Sua implicação está no contato do pesquisador com a realidade investigada (STAKE, 2011). Para Taylor e Bogdan (1984), o investigador deve estar completamente envolvido no campo de ação dos investigados, uma vez que, na sua essência, o método qualitativo se baseia principalmente em conversar, ouvir e permitir a expressão livre dos participantes.

Freitas (2002, p. 28) também compreende que "é necessário inicialmente uma aproximação, ou melhor, uma imersão no campo para familiarizar-se com a situação ou com os sujeitos a serem pesquisados". Geertz (1979, p. 241) refere-se ao trabalho de campo como "estar dentro do mundo do sujeito [...]; não como uma pessoa que sabe tudo, mas como alguém que quer aprender". E ainda, "não como uma pessoa que quer ser como o sujeito, mas como alguém que procura saber o que é ser como ele. Trabalha para ganhar a aceitação do sujeito, não como um fim em si, mas porque isto abre a possibilidade de prosseguir os objetivos da investigação" (GEERTZ, 1979, p. 241). 
Diante disso, ressalta-se a importância da permanência do pesquisador no espaço da investigação-formação. Essa imersão pode ser entendida como fundamental no processo de construção da investigação e na constituição do pesquisador. Molon (2008) salienta que o pesquisador vai se constituindo na trajetória da investigação e é constituído pelos outros envolvidos, direta ou indiretamente. Assim, por meio da convivência com os sujeitos, é possível estabelecer uma relação dialógica, como maneira de interação e aprendizado, em um espaço criado pelo ambiente natural dos envolvidos. Freitas reafirma a importância do diálogo entre investigador e investigado:

\begin{abstract}
isso muda tudo em relação à pesquisa, uma vez que investigador e investigado são dois sujeitos em interação. O homem não pode ser apenas objeto de uma explicação, produto de uma só consciência, de um só sujeito, mas deve ser também compreendido, processo esse que supõe duas consciências, dois sujeitos, portanto, dialógico (FREITAS, 2002, p. 24-25).
\end{abstract}

A terceira característica da pesquisa qualitativa é ser situacional, uma vez que "cada local e momento possui características específicas que se opõem à generalização" (STAKE, 2011, p. 25). Em uma investigação, por exemplo, não se trata de qualquer grupo de sujeitos professores de Matemática, nem de todos os grupos de sujeitos professores de Matemática. Cada grupo configura um contexto situacional único, com suas peculiaridades e histórias de vida, em relação a outros grupos, ainda que com características similares.

O mesmo ocorre com os dados trabalhados, que não se podem generalizar e transferir para outros contextos. Admitem apenas que se teçam generalidades sustentadas por articulações efetuadas sucessivamente com os sentidos do que está sendo expresso. (BICUDO, 2012).

A última característica implica que o estudo qualitativo é personalístico, empático, voltado a compreender as percepções individuais dos sujeitos. O pesquisador faz parte da própria situação de pesquisa e geralmente torna-se o principal instrumento da sua investigação ao "observar ações e contextos e ao desempenhar intencionalmente uma função subjetiva no estudo, utilizando sua experiência pessoal em fazer interpretações”. (STAKE, 2011, p. 30).

Portanto, a partir desses princípios orientadores da pesquisa qualitativa, assumese que o pesquisador tem possibilidades de aprender, de transformar-se e de ressignificarse durante o processo de pesquisa. $\mathrm{O}$ mesmo acontece com o pesquisado, que, não sendo coisa, mas sujeito, também tem a oportunidade de refletir, de aprender e de transformarse no transcorrer da pesquisa (FREITAS, 2009). 
Dentre as metodologias de pesquisa qualitativa, destaca-se a ATD, a qual corresponde a uma metodologia de análise de informações discursivas, com a finalidade de produzir novas compreensões em relação a determinados objetos de estudo (MORAES; GALIAZZI, 2011). O item a seguir explicita o processo de desenvolvimento dessa metodologia na pesquisa realizada.

\section{Desenvolvimento da ATD na pesquisa qualitativa}

Iniciou-se um movimento de reflexões e análise em torno das informações discursivas produzidas na pesquisa, com um olhar centrado na interrogação que delineou todas as ações da pesquisadora: que sentidos constroem os professores de Matemática em formação acadêmico-profissional em relação ao aprender com e sobre a linguagem escrita praticada no espaço formativo do PIBID/Matemática/FURG? Tal movimento de análise foi constituído por quatro focos, conforme Moraes e Galiazzi (2011): desmontagem dos textos, estabelecimento de relações, captação do novo emergente e processo autoorganizado.

O primeiro movimento, também denominado de processo de unitarização, corresponde à desconstrução das informações discursivas e à reconstrução de uma multiplicidade de sentidos pelo pesquisador. Teve início com a leitura de todas as produções textuais produzidas, as quais "constituem significantes a que o analista precisa atribuir sentidos e significados" (MORAES, 2003, p. 192), ou seja, foi um exercício de elaborar sentidos a partir do que o outro expressou.

Porém, ao realizar-se a leitura, observou-se que alguns materiais textuais abordavam uma repetição das informações, o que não acrescentaria modificações nos resultados. Logo, diante da amplitude das informações discursivas disponíveis, foi necessário fazer uma seleção e delimitação desse material. Moraes e Galiazzi (2011) esclarecem que nem sempre se trabalha com todo o corpus; por vezes, é preciso definir uma amostra a partir de um conjunto maior de textos. O Quadro 1 apresenta uma síntese das informações discursivas selecionadas.

Quadro 1: Informações discursivas selecionadas

\begin{tabular}{|l|l|}
\hline Etapas de produção & Informações discursivas \\
\hline Proposta & Escrita de histórias de vida $^{7}$ \\
\hline
\end{tabular}

\footnotetext{
${ }^{7}$ Produção textual originada da prática “A arte de escrever e contar a minha história”. Mais detalhes em Antiqueira e Machado (2017b).
} 


\begin{tabular}{|l|l|}
\hline Movimentando-se com a Escrita & Depoimentos produzidos por escrito $^{8}$ \\
\hline Conversa & Textos originados das transcrições \\
\hline
\end{tabular}

Fonte: autoras

Entendeu-se que esse conjunto de informações discursivas tinha a capacidade de produzir resultados válidos e representativos, tendo-se em vista o objetivo da investigação. O movimento interpretativo da análise continuou com a imersão no material textual, como proposto por Moraes e Galiazzi (2011). A intenção foi destacar as unidades de sentido, as quais são definidas por fragmentos dos textos e em acordo com o objetivo da pesquisa.

“As unidades são sempre identificadas em função de um sentido pertinente ao propósito da pesquisa" (MORAES; GALIAZZI, 2011, p. 19), sendo, dessa maneira, entendidas pela pesquisadora como elementos importantes, que expressam os sentidos dos sujeitos participantes em relação às suas aprendizagens. Nesse processo de desconstrução, foi necessário vencer a insegurança inicial e aos poucos conseguir captar os sentidos quanto ao que os sujeitos diziam, deixando vir à tona a desordem necessária para o surgimento de novas compreensões.

Esse momento da fragmentação envolveu importantes decisões, pois foi necessário delinear a amplitude das unidades, de modo a perceber os sentidos expressos em diferentes limites de seus pormenores. Estava-se diante de um material textual amplo, e, por isso, houve uma fragmentação, com menor ou maior intensidade, mas sempre ressaltando aspectos significativos do fenômeno pesquisado e tendo como referência o todo. Ademais, teve-se o cuidado de não fragmentar demais o texto em excertos isolados, a fim de não limitar a interpretação do fenômeno investigado.

As unidades de sentido foram organizadas em uma planilha eletrônica, para então ser feita a codificação de cada uma delas, com a intenção de associá-las aos seus textos originais. Para isso, cada sujeito foi identificado por seu pseudônimo, seguido de um índice contendo as iniciais de onde o fragmento foi extraído, a saber: DE para os Depoimentos Escritos, SÍNTESEHV para as Sínteses das Histórias de Vida e C para a Conversa.

Quando se tratou de um DE, também foi utilizada no índice a letra P, seguida do numeral romano que indica de qual prática foi retirada a unidade; por exemplo: PI, PIV,

\footnotetext{
${ }^{8}$ Produções textuais originadas de cinco práticas de escrita realizadas. São elas: "Escrevendo histórias e dialogando com outras histórias"; "Experimento dos retângulos"; "Da geometria à escrita: o ensinar e o aprender"; "Matemática em HQ"; e "Indo à sala de aula". Mais detalhes em Antiqueira (2018).
} 
PV, PVI e PVII. A sequência de cada unidade de sentido foi identificada por algarismos arábicos. O exemplo BrunaDEPIV06 indica que a unidade de sentido é um fragmento da escrita da professora em formação acadêmico-profissional Bruna, extraído dos depoimentos escritos, da prática IV, localizado na sexta unidade.

Sobre a importância da criação dos códigos, Moraes e Galiazzi (2011) reforçam que a elaboração de um sistema de códigos permite ao pesquisador identificar os textos originais e suas unidades de sentido, assim como outros elementos que fazem parte da análise, sempre que for necessário. No caso da análise expressa neste artigo, a codificação das unidades de sentido teve o desafio de indicar o material textual que originou cada uma das unidades, o que foi feito por meio das siglas relacionadas a cada material, e de mostrar a localização das unidades no interior de cada texto, indicada por um numeral. $\mathrm{O}$ Quadro 2 apresenta um recorte do processo de unitarização realizado, contendo exemplos da codificação e das unidades de sentido.

Quadro 2: Unitarização - codificação e unidades

\begin{tabular}{|c|l|}
\hline Codificação & \multicolumn{1}{c|}{ Unidades de sentido } \\
\hline Carlos & \multicolumn{1}{c|}{$\begin{array}{c}\text { ApEPI01 } \\
\text { identificamos com algum personagem e assim analisamos criticamente as situações } \\
\text { por eles vivenciadas e buscamos melhorar as nossas práticas futuras. }\end{array}$} \\
\hline \multirow{5}{*}{ LetíciasínTESEHV01 } & $\begin{array}{l}\text { Narra que o período da graduação foi dedicado, na sua maioria, às disciplinas de } \\
\text { cálculo, álgebra e geometria e que não havia muito incentivo para um estudo que } \\
\text { desse a ela a oportunidade de pensar sobre a escola. Isso veio a acontecer em sua } \\
\text { formação no PIBID, onde pode viver o ambiente escolar e pensar sobre a realidade } \\
\text { da escola. Ressalta que, a partir dessas reflexões, obrigou-se a escrever e registrar } \\
\text { suas ideias, acompanhada de leituras. Assim, Letícia diz que o PIBID contribuiu } \\
\text { para que voltasse a pensar e escrever sobre a escola e seus aprendizados. }\end{array}$ \\
\hline $\begin{array}{l}\text { Uma coisa que me ajudou e que gostei foi de fazer as atividades em grupo. Teve } \\
\text { uma escrita final, aquela do relato da prática da última atividade em que tivemos que } \\
\text { ir à escola. Esse relato foi escrito em grupo, então, como fizemos? Cada um escreveu } \\
\text { um pouco, fez uma parte. Só que, mesmo assim, a gente discutiu o que ia ser } \\
\text { colocado, o que foi mais importante. Então, a escrita em grupo ajudou nisso, [...]. }\end{array}$ \\
$\begin{array}{l}\text { Ajudou a discutir as ideias que iam ser colocadas no relato. Cada um pensava uma } \\
\text { coisa, a gente nem sempre pensa a mesma coisa. Então, tivemos que resumir, fazer } \\
\text { uma síntese do que a gente ia colocar na escrita do relato. Foi uma socialização do } \\
\text { que cada um pensava. }\end{array}$ \\
\hline
\end{tabular}

Fonte: autoras

Ainda no processo de unitarização, foi realizada a descrição de cada uma das unidades de sentido, com o objetivo de explicitar seus sentidos a partir do contexto em que foram produzidas. $\mathrm{O}$ exercício da descrição das unidades constitui "interpretações do pesquisador cada vez mais marcadas por sua autoria" (MORAES; GALIAZZI, 2011, p. 71). Na sequência da análise, foram atribuídos enunciados para as unidades de sentido, com vistas a apresentar sua ideia central. Para ampliar a compreensão do leitor, a seguir, 
é mostrado o Quadro 3, que apresenta um recorte das etapas realizadas no processo de análise pela ATD.

Quadro 3: Unitarização - enunciado e descrição

Unidades de sentido, codificação e enunciado Aprendi que no exercício de escrever e ouvir as histórias (de sala de aula) nos identificamos com algum personagem e assim analisamos criticamente as situações por eles vivenciadas e buscamos melhorar as nossas práticas futuras. Carlos DEPI01

\section{APRENDI, NO EXERCÍCIO DE ESCREVER AS HISTÓRIAS, A ANALISAR CRITICAMENTE AS SITUAÇÕES VIVENCIADAS E MELHORAR AS PRÁTICAS FUTURAS.}

Narra que o período da graduação foi dedicado, na sua maioria, às disciplinas de cálculo, álgebra e geometria e que não havia muito incentivo para um estudo que desse a ela a oportunidade de pensar sobre a escola. Isso veio a acontecer em sua formação no PIBID, onde pôde viver o ambiente escolar e pensar sobre a realidade da escola. Ressalta que, a partir dessas reflexões, obrigou-se a escrever e registrar suas ideias, acompanhada de leituras. Assim, Letícia diz que o PIBID contribuiu para que voltasse a pensar e escrever sobre a escola e seus aprendizados. LetíciasíNTESEHV01

\section{PENSAR SOBRE A REALIDADE DA ESCOLA}

Uma coisa que me ajudou e que gostei foi de fazer as atividades em grupo. Teve uma escrita final, aquela do relato da prática da última atividade em que tivemos que ir à escola. Esse relato foi escrito em grupo, então, como fizemos? Cada um escreveu um pouco, fez uma parte. Só que, mesmo assim, a gente discutiu o que ia ser colocado, o que foi mais importante. Então, a escrita em grupo ajudou nisso, [...]. Ajudou a discutir as ideias que iam ser colocadas no relato. Cada um pensava uma coisa, a gente nem sempre pensa a mesma coisa. Então, tivemos que resumir, fazer uma síntese do que a gente ia colocar na escrita do relato. Foi uma socialização do que cada um pensava. Larisse ${ }_{\mathrm{C} 21}$

\section{A ESCRITA EM GRUPO AJUDOU A DISCUTIR AS IDEIAS QUE IAM SER COLOCADAS NO RELATO E A SOCIALIZAR O QUE CADA UM PENSAVA}

Descrição

Essa unidade expressa que tanto a escrita das histórias de sala de aula, quanto a audição das histórias dos colegas, possibilitaram ao professor em formação se identificar com os personagens e analisar as situações que esses vivenciaram, para então, tentar melhorar a sua prática. Isso foi possível, pois, a cada narrativa compartilhada, fez-se um diálogo de modo a problematizar os acontecimentos presentes. A escrita da história também possibilitou que o professor em formação refletisse sobre sua prática profissional.

Letícia expressa que, enquanto aluna do curso de licenciatura em Matemática, sua preocupação era com as disciplinas voltadas à Matemática. Porém, participar do PIBID aproximou-a da escola, fazendo que surgissem momentos de reflexão sobre a experiência escolar. Diante disso, a professora em formação passou a sentir a necessidade de escrever e pensar no que estava aprendendo.

Essa unidade revela que as práticas de escrita realizadas em grupo foram importantes e que possibilitaram aprendizagens aos professores em formação. Mesmo sendo um relatório por grupo e cada componente escrevendo um pouco, eles tiveram que discutir o que deveria ser escrito no relatório. Foram momentos de socialização em que cada um teve que expor sua opinião, defender argumentos, até sintetizarem as ideias a serem escritas.

\section{Fonte: autoras}

O segundo movimento da análise foi o exercício da categorização, sem adotar categorias a priori, o que constituiu na comparação constante entre as unidades de sentido, levando ao agrupamento de elementos semelhantes (MORAES; GALIAZZI, 2011). 
Assim, o estabelecimento de relações e a reunião dos elementos em comum resultaram na constituição de 57 categorias iniciais. Cada categoria foi nomeada com uma frase que explicitasse uma nova compreensão, um conceito abrangido e sintetizado por todas as unidades de sentido e enunciados pertencentes à categoria.

Nesse momento, foi necessário ter um olhar longínquo para as unidades de sentido e categorias iniciais, com a intenção de repensar todo o caminho percorrido e os objetivos da pesquisa. Como salientam Moraes e Galiazzi (2011, p. 175), “de vez em quando é preciso deixar os dados descansarem um pouco, dar tempo a auto-organização entrar em ação"; assim, de maneira natural, o quebra-cabeça vai se constituindo.

Em um envolvimento intensivo com o material textual e o retorno constante às categorias iniciais, foi feito um novo agrupamento, dessa vez em um nível mais abrangente. Esse movimento originou 12 categorias intermediárias. À medida que se avançava na categorização, teve-se o desafio de expressar, para cada categoria intermediária, os argumentos parciais. Estes foram construídos de modo a aglutinar o conjunto de categorias e as unidades de sentido que as contituem.

Todas as categorias foram organizadas a partir da semelhança que as aproxima, e o nome atribuído a cada uma das categorias exprime a compreensão da pesquisadora diante do exercício da ATD e do objetivo da investigação. Destaca-se, ainda, que o conjunto de categorias representou adequadamente os sujeitos da pesquisa qualitativa realizada, o que permitiu melhorar a compreensão do fenômeno investigado.

As categorias intermediárias, por sua vez, foram reintegradas, constituindo um grupo de quatro categorias finais. São elas: 1) a linguagem escrita proporciona um “espaço de encontro" no PIBID Matemática por meio da mediação de processos interativos e coletivos potencializados; 2) a linguagem escrita, para além da formação universitária, implica o constituir-se professor de Matemática; 3 ) a prática da linguagem escrita, exercida na formação acadêmico-profissional, influencia no modo de escrever de professores de Matemática; e 4) o escrever é uma provocação ao pensar, propiciado pelo expressar-se, pela releitura e pelas interlocuções estabelecidas. Um recorte do processo de categorização pode ser acompanhado no Quadro 4, a seguir.

Quadro 4: Categorização

\begin{tabular}{|l|c|c|}
\hline \multicolumn{1}{|c|}{ Categorias iniciais } & $\begin{array}{c}\text { Categorias } \\
\text { intermediárias }\end{array}$ & Categorias finais \\
\hline $\begin{array}{l}\text { - Socialização de narrativas possibilita a } \\
\text { interação entre os colegas e uma melhor } \\
\text { convivência. }\end{array}$ & $\begin{array}{c}\text { Interação social } \\
\text { mediada pela } \\
\text { prática da escrita }\end{array}$ & $\begin{array}{c}\text { A linguagem escrita } \\
\text { proporciona um “espaço } \\
\text { de encontro" no PIBID }\end{array}$ \\
\hline
\end{tabular}




\begin{tabular}{|c|c|c|}
\hline $\begin{array}{l}\text { - Momentos de interação e o compartilhar } \\
\text { opiniões e tarefas. } \\
\text { - Aprender a trabalhar e a escrever em grupo. } \\
\text { - Gosto pelo trabalho coletivo. } \\
\text { - Interação com alunos da educação básica. }\end{array}$ & & \multirow[t]{3}{*}{$\begin{array}{c}\text { Matemática: processos } \\
\text { interativos e coletivos } \\
\text { potencializados }\end{array}$} \\
\hline $\begin{array}{l}\text { - A prática da escrita permite ouvir e opinar } \\
\text { mais. } \\
\text { - Importância de conhecer a escrita do outro. } \\
\text { - Escrita como um espaço de encontro. } \\
\text { - A escrita revela o pensamento de cada } \\
\text { integrante. }\end{array}$ & $\begin{array}{c}\text { Escrita como um } \\
\text { espaço de encontro e } \\
\text { de escuta }\end{array}$ & \\
\hline $\begin{array}{l}\text { - A atividade em grupo facilita a escrita. } \\
\text { - As dúvidas e inseguranças na escrita são } \\
\text { amenizadas pelo coletivo. } \\
\text { - As ideias se complementam, e, junto, a } \\
\text { escrita fica melhor. } \\
\text { - Na escrita em grupo, tem as contribuições } \\
\text { dos colegas. } \\
\text { - A escrita em grupo proporciona discutir } \\
\text { ideias que servem como resposta do coletivo. }\end{array}$ & $\begin{array}{l}\text { Dificuldade na } \\
\text { escrita amenizada } \\
\text { pelo coletivo }\end{array}$ & \\
\hline
\end{tabular}

Fonte: autoras

O terceiro movimento da análise, denominado de captura do novo emergente, consistiu na expressão dos resultados da pesquisa qualitativa por meio da construção de um texto interpretativo ou metatexto para cada uma das categorias finais. De acordo com Moares e Galiazzi (2011), os diferentes tipos de textos produzidos por meio da ATD possuem ênfases diversificadas em descrição e interpretação. Alguns são mais descritivos, mantendo-se mais próximos do corpus analisado; já outros são mais interpretativos e buscam um afastamento maior do material original.

Diante disso, o metatexto constitui-se pelo intenso exercício de escrita argumentativa para comunicar as compreensões atingidas; inclusive, pode-se dizer que todo o processo da análise, via ATD, culmina na elaboração do metatexto. Moraes e Galiazzi (2016, p. 53) argumentam que "a pretensão não é o retorno aos textos originais, mas a construção de um novo texto, um metatexto que tem sua origem nos textos originais, expressando a compreensão do pesquisador sobre os significados e sentidos construídos a partir deles".

Sua estruturação não é uma simples junção de partes e deve estar relacionada com as unidades de significado e as categorias, resultantes dos processos de unitarização e categorização. Para os autores da metodologia, o metatexto é

mais do que uma soma de categorias. Dentro dessa perspectiva, um metatexto, mais do que apresentar as categorias construídas na análise, deve constituir-se a partir de algo importante que o pesquisador tem a dizer sobre o fenômeno que investigou, um argumento aglutinador construído a partir da impregnação com o fenômeno e que representa o elemento central da criação do pesquisador. Todo texto necessita ter algo importante a dizer e defender e deveria expressá-lo com o máximo de clareza e rigor (MORAES; GALIAZZI, 2016, p.62). 
$\mathrm{Na}$ pesquisa expressa nesse artigo, para cada categoria final, foi elaborado um metatexto, que tem como estrutura básica as categorias intermediárias e as categorias iniciais. Também fizeram parte do metatexto as unidades de sentido associadas às categorias. Ainda sobre a estrutura do metatexto, Moraes e Galiazzi (2016, p. 54-55) complementam: "uma vez construídas as categorias, estabelecem-se pontes entre elas, investigam-se possíveis sequências em que poderiam ser organizadas (...)”. Além disso, foram construídos textos parciais para as diferentes categorias, sendo posteriormente integrados na estruturação do metatexto como um todo.

Outro ponto importante a destacar sobre a estrutura de um metatexto é a necessidade de uma introdução e de um fechamento, de maneira a facilitar a compreensão das ideias expressas no texto. Associado a isso, o pesquisador deve retomar constantemente a produção em seu todo, ou em suas partes, submetendo-a a críticas e reformulações, com vistas a uma escrita cada vez mais aprimorada (MORAES e GALIAZZI, 2011).

O quarto movimento da análise compreende, em seu todo, um processo autoorganizado, do qual emergem as compreensões e as aprendizagens. Para Moraes (2003), a análise textual qualitativa pode ser compreendida como um processo auto-organizado de construção de novos significados em relação a determinados objetos de estudo, a partir de materiais textuais referentes a esses fenômenos. Nesse sentido, é um efetivo aprender, um aprender auto-organizado (MORAES, 2003).

Diante dos movimentos realizados na análise, a produção dos metatextos permitiu ampliar o entendimento em relação ao fenômeno investigado, a partir do intenso diálogo com os interlocutores empíricos e teóricos e da expressão dos argumentos construídos pela pesquisadora. Para ilustrar essa etapa, apresenta-se, posteriormente, o recorte de um dos metatextos produzidos na pesquisa qualitativa.

\section{Metatexto: A linguagem escrita proporciona um "espaço de encontro" no PIBID}

\section{Matemática: processos interativos e coletivos potencializados ${ }^{9}$}

O docente raramente atua sozinho, pois sua atividade não é exercida sobre um objeto, e sim realizada em uma rede de interações com outras pessoas, em um contexto onde o elemento humano é dominante e estão presentes diversos sentimentos e atitudes

\footnotetext{
${ }^{9} \mathrm{O}$ metatexto apresenta excertos analisados em diálogo com os autores vinculados ao campo teórico da formação de professores e da linguagem escrita.
} 
(TARDIF, 2014). Defende-se, então, que a linguagem escrita proporciona um "espaço de encontro" no PIBID Matemática por meio da mediação de processos interativos e coletivos potencializados. Diante desse argumento, faz-se uma discussão em torno de três ${ }^{10}$ aspectos manifestados pelos professores de Matemática em formação acadêmicoprofissional; são eles: interação social mediada pela prática da escrita; escrita como um espaço de encontro e de escuta; e dificuldade na escrita amenizada pelo coletivo.

Em relação ao primeiro aspecto, a interação social mediada pela prática da escrita, ressalta-se a capacidade do ser humano de interagir e, consequentemente, de aprender em diferentes grupos e esferas sociais. No âmbito da formação de professores, em específico no PIBID/Matemática/FURG, não é diferente, na medida em que se assume a dimensão sociointeracional da linguagem escrita, a qual se constitui um artefato interativo que propicia a socialização de todos os envolvidos.

Essa compreensão pôde ser constatada por meio das práticas de escrita desenvolvidas no subprojeto, as quais foram mediadoras na interação entre os professores de Matemática em formação acadêmico-profissional. Em um dos momentos experienciados, a socialização de narrativas possibilitou a interação entre os colegas e uma melhor convivência, conforme ilustra o seguinte depoimento: "Ao compartilhar as histórias (de sala de aula), estamos interagindo com os nossos colegas, o que possibilita

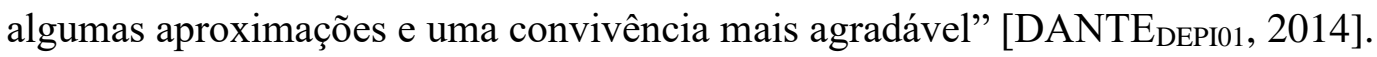

Além do mais, muitas narrativas produzidas estavam relacionadas com as atividades desenvolvidas pelos professores de Matemática em formação acadêmicoprofissional no PIBID e/ou com suas experiências pessoais e profissionais, como fatos ocorridos na época da escola ou nos estágios supervisionados realizados na graduação. Esses elementos possibilitaram momentos de partilha, de acolhimento da narrativa do outro e, consequentemente, de aproximação e convivência agradável entre os pares, conforme a referência que Dante faz em seu depoimento.

O movimento de interação e melhor convivência decorrente da socialização das narrativas aproxima-se da visão interacionista da linguagem escrita defendida por Antunes (2003), que supõe o encontro, a parceria, o envolvimento entre sujeitos, para que aconteça a comunhão de ideias, das informações e das intenções ao escreverem. A presença de cada professor em formação na roda do subprojeto Matemática também teve sua importância, pois os professores puderam contribuir com o enredo das histórias,

\footnotetext{
${ }^{10}$ Como se trata de um recorte do metatexto, neste artigo, fez-se a escolha de não abordar o segundo aspecto. O leitor pode ler o metatexto na íntegra em Antiqueira e Machado (2019).
} 
inclusive, com sugestões de títulos e palavras, colaborando com o aprimoramento da escrita das narrativas.

Outro ponto salientado pelos professores de Matemática em formação acadêmicoprofissional refere-se aos momentos de interação e ao compartilhar de opiniões e tarefas. De acordo com o depoimento de Carlos:

\begin{abstract}
$\mathrm{Na}$ atividade experimento dos retângulos, tive a oportunidade de trabalhar em grupo com duas colegas pibidianas com as quais não havia trabalhado em conjunto, pois visitamos escolas diferentes. Com isso, percebo que as atividades realizadas em cada reunião semanal do PIBID também possibilitam esse momento de interação e vivência entre os grupos de bolsistas, permitindo a troca de saberes, opiniões e divisão de tarefas [CARLOS ${ }_{\text {DEPIV01, 2015]. }}$
\end{abstract}

Na prática de escrita destacada por Carlos, os participantes foram desafiados a interagir e dialogar com as ideias dos demais colegas, em um exercício de ampliar seus conhecimentos individuais a partir do caminhar coletivo de cada grupo. Ao encontro disso, o processo de interação precisa ser compreendido dentro de uma dinâmica entre os sujeitos, na qual os significados emergem em decorrência de uma ação conjunta, resultante dos (des)encontros de diferentes níveis de conhecimento (SARMENTO, 2006).

Diante do contexto de interação social mediada pela prática da escrita, as palavras de Carlos explicitam o sentimento de como ele é afetado pela ação conjunta entre seus pares. Isto ressalta o quanto foi importante realizar a atividade com as duas colegas, com quem ainda não havia tido a oportunidade de trabalhar. Carvalho $(2009$, p. 15) entende que, quando se interage com uma ou mais pessoas, isso pressupõe que se trabalhe "em conjunto com o outro, e quando se trabalha colaborativamente espera-se que ocorram certas formas de interacções sociais responsáveis pelo activar de mecanismos cognitivos de aprendizagem, como a mobilização de conhecimentos". Logo, o momento de interação entre Carlos e as duas colegas produziu aprendizagens para os três, possibilitando-lhes a partilha, o diálogo e a construção de saberes.

No PIBID/Matemática/FURG, a maioria das práticas de escrita desenvolvidas demandou uma organização em subgrupos. Em algumas situações, os critérios foram livres; em outras, as escolhas ocorreram com base nos grupos já formados por escola participante do PIBID. Assim sendo, os modos de interação foram bastante diversificados - entre cada participante e todo o grupo; entre os subgrupos; entre os participantes de cada subgrupo -, além da interação de todos com as pesquisadoras e com os demais envolvidos na experiência.

Os integrantes também consideraram a importância do trabalho em grupo. Para Dante, "a parte de trabalhar em grupo, quando se forma um grupo bom, é excelente, ajuda 
muito, porque sempre que tem pessoas conectadas num mesmo sentido, vai para a frente. Agora, do contrário, não vai" [DANTE $\mathrm{D} 25,2016]$.

Os professores de Matemática em formação acadêmico-profissional reconhecem que, a partir das experiências vividas no subprojeto Matemática, estar na companhia do outro foi um fator potencializador para o aprender. A convivência grupal e as trocas entre os pares proporcionaram momentos significativos para o aprendizado, tanto pessoal quanto profissional, dos integrantes. De fato, segundo Jaramillo, Freitas e Nacarato (2009, p. 182), "estudos vêm apontando a importância dos grupos como instâncias altamente potenciais para o desenvolvimento profissional dos professores".

Além das aprendizagens possibilitadas por estarem em grupo, os participantes manifestaram o gosto pelo trabalho coletivo. Destaca-se esse aspecto no fragmento: "Gostei também de fazer as atividades do PIBID em grupo, as gurias são bem tranquilas, deu certo. O problema é quando as duplas não se encaixam, não pode é 'ah, eu quero isso e quero aquilo'. Então, trabalhar em grupo é importante porque vai nos preparar mais" [BRUNACI16, 2016].

No relato, Bruna destaca que gostou de realizar as atividades no coletivo e demonstra satisfação com as colegas de seu grupo. Alguns fatores são responsáveis por esse contentamento, como a "voluntariedade e a participação espontânea indicada na predisposição dos participantes em trabalharem juntamente (...) e pelo desejo de fazerem parte de um determinado grupo" (ALMEIDA; MEGID, 2017, p. 178).

Há de se considerarem os diferentes pensamentos e saberes relacionando-se, tendo em vista que cada integrante de um grupo trabalha, convive e/ou participa a partir e por meio daquilo que traz, como os conhecimentos, as sensibilidades e os sentidos de vida, originados de suas experiências pessoais e interativas (BRANDÃO, 2005). Portanto, as práticas de escrita permitiram que vínculos se efetivassem e que aprendizagens fossem construídas por meio da relação e da interação entre os integrantes do subprojeto Matemática.

Outro fator emergente foi a interação dos professores de Matemática em formação acadêmico-profissional com alunos da educação básica em uma das práticas de escrita realizadas, em que foram elaboradas atividades envolvendo Matemática e escrita, e desenvolvidas em escolas do Ensino Fundamental e Médio. Bruna manifesta essa ideia de interação em seu depoimento ao referir-se à construção de histórias coletivas:

Levamos o tangram impresso em uma folha e propomos a eles (alunos do $5^{\circ}$ ano de uma escola de ensino médio) que pintassem e recortassem para que cada um montasse uma figura, para então criarem uma história coletiva ou em 
grupo. Começamos com a história coletiva, pois a mesma seria mais rápida, mas a mesma não deu muito certo, aí, resolveram fazer em grupo, e alguns até individualmente. No total, foram feitas três histórias e as mesmas foram usadas para construir uma única história, conjuntamente, por nós, professoras. [BRUNA

Bruna expressou o quanto a atividade foi desafiadora e um pouco complexa, na medida em que a escrita da história coletiva "não deu muito certo". Alternativas tiveram que ser almejadas pelos integrantes, fazendo com que, inicialmente, pequenos grupos criassem suas histórias para, na sequência, produzirem uma única história. Assim, a interação com os alunos foi permeada por diálogos e ações conjuntas, o que contribuiu para iniciativas tanto individuais quanto coletivas.

Assim sendo, assume-se a linguagem escrita como movimento e produção histórico-social que se realiza na interação entre os sujeitos. A partir das ideias vigotskianas, tem-se o entendimento de que o ser humano não pode ser compreendido como passivamente moldado pelo meio, nem apenas ativo: trata-se de um sujeito interativo. Sua autonomia e a regulação de suas ações constroem-se sobre interações (GÓES, 1991).

O terceiro aspecto que emergiu no discurso dos professores de Matemática em formação acadêmico-profissional refere-se à dificuldade na escrita amenizada pelo coletivo. Segundo Rodrigues (2011, p. 32), o trabalho coletivo oportuniza "trocas de opiniões, tempo dedicado às discussões e à execução de tarefas. [...] seja com os alunos, seja com seus pares, mostra a sua contribuição no valor das relações grupais como elemento importante no convívio humano". Decorre daí, então, a importância de se pensar nos integrantes do PIBID/Matemática/FURG enquanto sujeitos que aprendem na interação, na convivência, no estar junto, intervindo no nível das suas dificuldades ao lidarem com a escrita.

Para Vigotski (2007), o conhecimento é construído nas interações dos sujeitos com o meio e com outros indivíduos; inclusive, essas interações são as principais promotoras da aprendizagem. Diante disso, pode-se afirmar que o coletivo propiciou aos professores em formação o aprender uns com os outros e que a atividade em grupo facilitou a escrita, conforme menciona uma participante: "pensar numa atividade, num planejamento envolvendo a matemática e a escrita, não foi fácil, mas, como a atividade foi feita em grupo, isso me ajudou" [CAMILAC12, 2016].

A atividade mencionada diz respeito a uma das etapas de uma prática em que foi solicitado às duplas um planejamento de aula vinculado a um conteúdo de Matemática e 
ao exercício da escrita. A colaboração entre pares na produção do planejamento foi favorável à participante Camila, conforme seu relato, pois fez com que suas dificuldades se tornassem menores. Isso aconteceu porque houve apoio dos demais colegas de grupo, estimulando seu potencial.

Essa situação de ajuda dos integrantes do grupo em que a professora em formação estava inserida foi imprescindível para seu aprendizado e desenvolvimento, além de contribuir para que, em um momento seguinte, ela conseguisse realizar as mesmas ações de forma independente e autônoma. É justamente na distância entre o que uma pessoa consegue fazer sozinha e o que pode fazer com alguma assistência que reside o nível de desenvolvimento proximal criado por Vigotski.

Em geral, as demais práticas coletivas de escrita realizadas no PIBID/Matemática/FURG e as da proposta "Movimentando-se com a escrita" favoreceram a aprendizagem na Zona de Desenvolvimento Proximal dos participantes, na medida em que o exercício da linguagem escrita foi mediado pela intervenção de pessoas mais experientes, criando momentos de interação e interlocução privilegiados.

Ampliando a discussão, os professores de Matemática em formação acadêmicoprofissional revelaram que as dúvidas e inseguranças na escrita são amenizadas pelo coletivo. Sobre isso, Mari diz que "gostaria de destacar as práticas realizadas em grupo. Penso que minhas dúvidas, inseguranças na hora de escrever, foram amenizadas com os colegas, e isso foi bom" [MARI $\left.{ }_{\mathrm{C} 15}, 2016\right]$. Na mesma perspectiva, Carolina menciona: "se eu tivesse que escrever sozinha, seria bem mais difícil, desistiria logo no primeiro obstáculo, fico com dúvida e acabo deixando de lado. Quando é com outra pessoa, acho melhor, pois me sinto mais segura de como escrever" [CAROLINA ${ }_{\mathrm{C} 19}, 2016$ ].

Observa-se que tanto Mari quanto Carolina consideram a presença dos colegas de grupo como sendo um ponto de apoio e de segurança para os momentos de dificuldade ao escrever. As possíveis dúvidas são compartilhadas com os demais professores em formação acadêmico-profissional, que, envolvidos na situação, vão buscando soluções para o que está sendo posto no momento da escrita. Assim, todos contribuem com suas experiências e conhecimentos individuais, mobilizados no momento em que estão escrevendo.

Os professores de Matemática em formação acadêmico-profissional também mencionaram que, ao escreverem coletivamente, suas ideias se complementam e a escrita fica melhor. O fragmento a seguir ilustra essa situação: 
Achei importante a experiência de trabalhar em grupo, porque até erros que se comete, e a outra pessoa viu, que eu não tinha conseguido perceber, e a outra pessoa viu, isso ajuda muito na realidade, né, porque cada um tem uma ideia e, às vezes, a tua ideia complementa a ideia do outro, e junto fica melhor a escrita, mais rico o texto, e o PIBID e a tua proposta sempre trabalharam isso em grupo [DANTE $\left.{ }_{\mathrm{C} 31}, 2016\right]$.

As palavras de Dante reforçam a relação de cooperação implicada no exercício da escrita coletiva, além da necessidade de se compreenderem os argumentos do colega em relação aos "erros" cometidos. A escrita coletiva é um artefato propulsor do conhecimento, da interação, do aprender. Ao encontro desse ponto de vista, Ferreira compreende que

(...) a produção coletiva de textos a partir do pressuposto de que a ação de ler e socializar a própria produção reflexiva, bem como os esboços da escrita do grupo, extravasam e ampliam o texto e seu contexto inicial, abrindo-o para o infinito. Assim, as ideias já não são mais de um único sujeito, mas daqueles que fazem do texto um exercício de polifonia: o seu texto modifica o meu texto; minhas palavras interferem no seu texto; dialogamos por meio de nossas escritas compartilhadas (FERREIRA, 2007, p. 228).

A polifonia mencionada pela autora refere-se às diferentes vozes que se agregam no ato da produção coletiva. É notório que nem todas as vozes são contempladas na construção de uma escrita. Há situações em que um dos integrantes toma a iniciativa de escrever, impondo apenas seu ponto de vista. Em outras, a escrita coletiva é composta pelas ideias individuais mais significativas. Ou ainda, como mencionou Dante, organizase uma única ideia, a ser escrita a partir do complemento das ideias individuais.

Além do mais, a escrita em grupo tem as contribuições dos colegas, conforme comenta Eloise:

\begin{abstract}
Eu gostei bastante da troca de experiência através da escrita, por exemplo, nós compartilhávamos com nossos colegas no PIBID, às vezes eu escrevia e trocava a minha escrita com a do colega, cada um lia a do outro para depois fazer uma análise do que ia ser usado no relatório. Quando eu preciso montar, escrever um planejamento, eu acho o trabalho em grupo bom, porque sempre tem as contribuições que teu colega pode fazer [ELOISE ${ }_{\mathrm{C} 20}, 2016$ ].
\end{abstract}

Observa-se que, conforme o depoimento de Eloise, a dinâmica de construção do relatório foi da escrita individual para a coletiva, e depois cada integrante socializou seu registro. Nesse caso, quando é socializada e incorporada ao coletivo, a escrita adquire novas formas, transforma-se. Esse movimento que parte da reflexão individual em direção à produção coletiva lembra que aprendemos com o outro, na mesma medida em que colaboramos com ele (FERREIRA, 2007). Ao escrever em grupo, cada professor auxilia com suas ideias, fazendo com que as dificuldades presentes no ato da escrita sejam amenizadas pelo coletivo. 
A escrita coletiva torna-se, assim, um processo aberto, em que a cada leitura podem surgir novas contribuições e modificações, sempre com a intenção de entender e ampliar o sentido do que está sendo exposto pelos autores. Nessa perspectiva, pensar a escrita como processo destaca seu caráter interativo e recursivo, em que a construção e o aperfeiçoamento do texto demandam diálogo, reflexão, reescritas e releituras.

Por conseguinte, a ação coletiva na proposta Movimentando-se com a escrita possibilitou aos professores de Matemática em formação acadêmico-profissional perceber que a escrita envolve o processo de geração de ideias, criatividade e planejamento sobre o que se deseja escrever, além de reflexão sobre as estratégias utilizadas durante a produção escrita. Nesse viés, a escrita em grupo proporciona discutir ideias que servem como resposta do coletivo. As palavras de Letícia vão ao encontro das reflexões apresentadas.

\begin{abstract}
As atividades em grupo foram interessantes, [...] justamente por possibilitarem uma escrita em grupo. Eu acredito que, quando escrevemos em grupo, estamos discutindo ideias, pensando em algo que servirá como resposta do coletivo, do grupo, para aquilo que solicitaste na atividade. Só que isso não é muito fácil. Por quê? Porque primeiramente o grupo tem que chegar a um consenso, a gente tem que socializar o que cada um pensa, e isso nos ajuda a defender nossos argumentos. Muitas vezes, eu não concordava com a ideia de uma colega, a gente quase discutia. Eu lembro que uma das atividades que eram em grupo eu fiz com a outra professora e mais dois licenciandos, e não teve nada de um escrever por todos, tudo foi bem democrático [LETÍCIA ${ }_{\mathrm{C1} 4}, 2016$ ].
\end{abstract}

Nesse trecho, Letícia retrata, em parte, como aconteceram as escritas coletivas em seu grupo. Antes de iniciar o registro, houve a busca pelo consenso, quando os professores em formação expressaram seus interesses e opiniões, encadeando debates e exteriorizando seus pontos de vista, incluindo também os momentos de divergências de ideias. Estes podem ser benéficos, na medida em que suscitam o diálogo e o desenvolvimento de habilidades argumentativas. Cabe aos componentes dos grupos ponderarem sobre os desacordos, principalmente por tratar-se de uma proposta de texto coletivo que deve expressar as ideias do grupo.

Segundo Almeida e Megid (2017), a dinâmica de inserir ideias de diferentes pessoas no mesmo texto faz com que os participantes do grupo tenham que interagir e compartilhar a experiência formativa em sua multiplicidade. E ainda, a discussão coletiva incrementa a reflexão e proporciona aprendizagens docentes. Larisse contribui com essa discussão ao falar que:

Uma coisa que me ajudou e que gostei foi de fazer as atividades em grupo. Teve uma escrita final, aquela do relato da prática da última atividade em que tivemos que ir à escola. Esse relato foi escrito em grupo, então, como fizemos? Cada um escreveu um pouco, fez uma parte. Só que, mesmo assim, a gente 
discutiu o que ia ser colocado, o que foi mais importante. Então, a escrita em grupo ajudou nisso, [...]. Ajudou a discutir as ideias que iam ser colocadas no relato. Cada um pensava uma coisa, a gente nem sempre pensa a mesma coisa. Então, tivemos que resumir, fazer uma síntese do que a gente ia colocar na escrita do relato. Foi uma socialização do que cada um pensava [LARISSE [211, 2016].

Observa-se que a construção do relato aconteceu, inicialmente, por meio da divisão de tarefas. Significa que cada integrante se responsabilizou por escrever um pouco, a partir da discussão coletiva do que deveria ser contemplado no texto. Mesmo sendo feita uma síntese das ideias a serem expressas no relato, a escrita de cada um foi compartilhada com os outros autores/colegas do grupo, tornando-a pública. Pode-se dizer que essa é uma das implicações da escrita coletiva: tornar pública a escrita dos autores. Nesse caso, “a ênfase está no processo de construção do texto, em que cada autor participa com as suas ideias e todos buscam construir sentidos" (BROCH, 2008, p. 46).

A partir das reflexões apresentadas, pode-se afirmar que as dificuldades dos professores de Matemática em formação em relação ao exercício da linguagem escrita foram amenizadas pelo coletivo. Diversos fatores, como o trabalho em equipe, o diálogo, as relações de autoria estabelecidas entre eles, as contribuições com a escrita do outro e a capacidade de argumentação, propiciaram o enfrentamento dos obstáculos existentes no ato da escrita. Foi na coletividade que eles enriqueceram as ideias a serem escritas e o vocabulário, o que promoveu desenvolvimento intelectual e social.

\section{Algumas aprendizagens possibilitadas pela Análise Textual Discursiva}

Dentre as aprendizagens que a ATD possibilita ao pesquisador, pode-se destacar a ampliação teórica. Os teóricos auxiliam a compreender a temática, ampliando as compreensões, problematizando aspectos pensados e favorecendo colocar em suspenso ideias antes pensadas. Diante disso, há a possibilidade de fazer emergir uma teorização a partir das categorias encontradas, assim como de evidenciar o conhecimento construído sobre o tema pesquisado.

No caso da pesquisa qualitativa realizada, a ATD propiciou à pesquisadora construir questionamentos sobre o tema da pesquisa, inquietar-se com algumas questões teóricas emergentes entre campo empírico e teórico, movimentar-se por leituras de diferentes perspectivas teóricas. Para isso, o aprofundamento das leituras realizadas levou à busca de informações acerca das inquietações, desfazendo-se certezas, saberes, pressupostos, e construindo-se outros, talvez provisórios. Isso resultou no exercício 
permanente de formação da pesquisadora, desde os princípios de autoria que foram necessários até o desenvolvimento da autonomia.

Em busca dessa ampliação teórica, procuraram-se compreensões teóricas da perspectiva histórico-cultural de Lev Vigotski, a qual permitiu pensar a formação docente como um processo mediado pelas relações interpessoais e a linguagem escrita como um instrumento além da comunicação, ou seja, um artefato que possibilita às pessoas aprenderem e se desenvolverem. No âmbito da formação de professores, pode-se avançar em compreensões em torno da formação como um processo inacabado que se dá em um continuum.

Uma característica importante a considerar na ATD é o constante exercício da escrita, que se constitui em um processo de aprendizagem e um modo de comunicação. A escrita torna-se instrumento do pensar que, ao mesmo tempo em que procura comunicar algo, promove uma evolução dos modos de pensar de quem nela se envolve (MORAES; GALIAZZI, 2011). Ao utilizar-se a ATD na pesquisa qualitativa mencionada neste artigo, diversas foram as situações em que a escrita se mostrou necessária. Uma delas foi o registro no processo de produção das informações discursivas, momento em que a pesquisadora permaneceu, aproximadamente, dois anos no campo empírico, em contato com os sujeitos. Nesse processo, a escrita auxiliou na intenção de capturar a experiência de "ter estado lá", proporcionando à pesquisadora o registro efetivo do que acontecia no espaço de investigação-formação PIBID/Matemática/FURG.

Em meio ao processo de análise pela ATD, a pesquisadora teve a oportunidade de visualizar, por meio da escrita, o próprio processo de aprendizagem e de pensar naquilo que compreendeu mediante as leituras da sua própria escrita. Dessa maneira, ao escrever e reler o escrito, o pesquisador pode significar suas ações e a si mesmo, encontrar outros sentidos e, com isso, aprender com a própria escrita. Ao escrever, múltiplas possibilidades de aprendizado são mobilizadas no escrevente (PRADO; SOLIGO, 2007; MARQUES, 2011).

$\mathrm{Na}$ ATD, o pesquisador é desafiado a escrever sempre mais. Isso porque a linguagem escrita permite ao pesquisador conhecer-se melhor, uma vez que favorece a reflexão sobre o que ele faz e pensa, a sistematização dos saberes que produz e o desenvolvimento da sua capacidade de escrever. Nesse sentido, Moraes e Galiazzi (2011, p. 194) argumentam que a escrita é uma ferramenta de reconstrução de conhecimentos, sendo considerada como um "duplo processo de aprender e comunicar". Os autores 
acreditam que a escrita implica a produção de conhecimentos, pois amplia a compreensão de algo que interessa a quem escreve. Desse modo,

[...] é importante reconhecer e valorizar dois processos complementares envolvidos na escrita: o comunicar algo e o reconstruir das compreensões que o processo envolve. [...] o escrever sempre mostra duas faces complementares, quais sejam, o expressar o já compreendido, juntamente com a construção de sempre novos modos de entender o que está sendo expresso. Numa produção escrita criativa e original o autor envolve-se simultaneamente com comunicar e aprender sobre o tema que escreve (MORAES; GALIAZZI, 2011, p. 197).

Além do aprender, é por meio da escrita que o pesquisador expressa e comunica os resultados da sua pesquisa, reescreve as unidades de sentido encontradas no primeiro movimento de análise e constrói as categorias, as quais precisam comunicar seus sentidos e argumentos de forma clara e convincente. Além disso, os registros decorrentes das leituras, do diálogo com os interlocutores teóricos na etapa de produção do metatexto, são movimentos necessários no processo de desenvolvimento da ATD. Destaca-se também a importância de realizar a leitura na íntegra do livro (MORAES; GALIAZZI, 2011), pois a cada leitura vão sendo ampliados os horizontes de compreensão necessária para o desenvolvimento da metodologia.

Portanto, a utilização dessa metodologia possibilita-nos pensar em como o pesquisador vai se constituindo nos desafios que vão sendo postos e na atenção e rigor necessários em cada etapa da análise. São múltiplos os caminhos em uma pesquisa, nos quais o pesquisador aprende a teorizar, a dialogar e a comunicar, em um processo de idas, vindas, descobertas e questionamentos permanentes propiciados pela ATD.

\section{Considerações}

As compreensões expressas neste artigo buscaram explicitar o percurso da utilização da ATD na pesquisa qualitativa que foi realizada no âmbito da formação de professores de Matemática. As etapas do desenvolvimento da metodologia foram descritas de modo gradual, visando a mostrar minuciosamente tudo que foi feito e compreendido na pesquisa. Porém, é essencial pensar na dimensão e amplitude da ATD para muito além de tudo que foi exposto e das compreensões relatadas.

Considerou-se importante exibir o recorte de um dos metatextos produzidos. A intenção foi justamente mostrar o exercício do intenso diálogo estabelecido com os interlocutores empíricos e teóricos, assim como a expressão dos argumentos necessários para comunicar as compreensões emergentes em uma pesquisa qualitativa. 
A intenção de relatar algumas aprendizagens proporcionadas pela ATD foi no sentido de reforçar a importância de alguns aspectos que a pesquisadora exercitou no processo de realização da análise, em especial, a escrita e tudo que com ela se aprende. Entende-se que essas aprendizagens estão articuladas ao contexto de pesquisa e às experiências de vida de cada pesquisador. A partir desse entendimento, cada pesquisador contém um aprender próprio de quem viveu o movimento da ATD em sua prática de pesquisa e por isso constrói uma série de sentidos e saberes sobre o que aprendeu.

Utilizar a ATD exige do pesquisador o conhecimento aprofundado da metodologia e um profundo exercício de sua subjetividade, a qual é própria do seu pensamento. $\mathrm{O}$ comprometimento também é necessário em todas as etapas da análise. O modo como a metodologia possibilita conduzir o pesquisar faz com que o pesquisador se sinta desafiado a ler e a escrever sempre mais e, principalmente, a aprender.

\section{Referências}

ALMEIDA, A. R.; MEGID, M. A. A escrita colaborativa na formação continuada de professores que ensinam Matemática. Inter-Ação, Goiânia, v. 42, n. 1, p. 176-193, jan./abr. 2017. Disponível em: http://dx.doi.org/10.5216/ia.v42i1.41858. Acesso em: 09 set. 2019.

ANTIQUEIRA, L. S.; MACHADO, C. C. Movimentando-se com a Escrita: uma proposta com professores em formação. In: MEMBIELA, P. et al. (org.). La enseñanza de las ciencias en el actual contexto educativo. Espanha: Educación Editora, 2017a. p. 605-609.

ANTIQUEIRA, L. S.; MACHADO, C. C. A arte de escrever e contar minha história: narrativas autobiográficas de professores em formação. Enseñanza de las ciencias: revista de investigación y experiencias didácticas, Sevilha, Número Extra, p. 2719-2724, set. 2017b. Disponível em: https://ddd.uab.cat/record/184101. Acesso em: 26 set. 2020.

ANTIQUEIRA, L. S. O aprender com e sobre a linguagem escrita no Pibid Matemática: sentidos construídos pelos professores de Matemática em formação acadêmico-profissional. 2018. Tese (Doutorado em Educação em Ciências) - Universidade Federal do Rio Grande, Rio Grande, 2018. Disponível em: https://argo.furg.br/?BDTD11903. Acesso em: 26 set. 2020.

ANTIQUEIRA, L. S.; MACHADO, C. C. A Linguagem Escrita Proporciona um "Espaço De Encontro" no PIBID Matemática: Processos Interativos e Coletivos Potencializados. Jornal Internacional de Estudos em Educação Matemática, Londrina, v. 12, n. 1, p. 38 - 50, abr. 2019. Disponível em: https://revista.pgsskroton.com/index.php/jieem/article/view/6237. Acesso em: 17 set. 2020.

ANTUNES, I. Aula de Português: encontro \& interação. São Paulo: Parábola Editorial, 2003.

BICUDO, M. A. V. Pesquisa Qualitativa; Significados e a Razão que a Sustenta. Revista

Pesquisa Qualitativa, São Paulo, ano 1, n.1, p. 7-26. 2005. Disponível em:

https://editora.sepq.org.br/index.php/rpq/article/view/7. Acesso em: 04 out. 2020. 
BICUDO, M. A. V. A pesquisa em educação matemática: a prevalência da abordagem qualitativa. Revista Brasileira de Ensino de Ciência e Tecnologia, Ponta Grossa, v. 5, n. 5. p. 15-26, mai./ago. 2012. Dispponível em: https://periodicos.utfpr.edu.br/rbect/article/view/1185. Acesso em: 26 set. 2020.

BICUDO, M. A. V. Pesquisa Fenomenológica em Educação: Possibilidades e desafios. Revista Paradigma, Venezuela, v. XLI, p. 30 - 56, jun. 2020. Disponível em: http://www.mariabicudo.com.br/resources/928-1252-1-PB.pdf. Acesso em: 25 set. 2020.

BOGDAN, R.; BIKLEN, S. Investigação qualitativa em Educação. Trad. Maria Alvarez; Sara Santos; Telmo Baptista. Portugal: Porto Editora, 1994.

BRANDÃO, C. Comunidade Aprendente. In: FERRARO JR, L. (org.). Encontros e Caminhos: formação de educadoras(es) ambientais e coletivos educadores. Brasília: MMA, Diretoria de Educação Ambiental, 2005. p. 83-92.

BRASIL. Lei no 12.796, de 4 de abril de 2013. 2013. Disponível em: http://www.planalto.gov.br/ccivil_03/_ato2011-2014/2013/lei/112796.htm. Acesso em: 15 set. 2020.

$\mathrm{BROCH}, \mathrm{I}$. K. Escrita coletiva de texto teatral em língua inglesa em ambiente virtual de aprendizagem: o foco do aluno no processo. 2008. 145f. Dissertação (Mestrado em Linguística Aplicada), Instituto de Letras, Universidade Federal do Rio Grande do Sul, Porto Alegre, 2008.

CARVALHO, C. Comunicações e interacções sociais nas aulas de Matemática. In: NACARATO, A. M.; LOPES, C. E. (org.). Escritas e leituras na Educação Matemática. Belo Horizonte: Autêntica, 2009. p. 15 - 34.

DINIZ-PEREIRA, J. E. A formação acadêmico-profissional: compartilhando responsabilidades entre as universidades e escolas. In: Encontro Nacional de Didática e Práticas de Ensino, 14, 2008, Porto Alegre. Anais do ENDIPE. Porto Alegre: PUCRS, 2008, p. 253-267.

FERREIRA, C. R. Uma experiência de produção coletiva de textos. In: PRADO, G. V. T.; SOLIGO, R. (org.) Porque escrever é fazer história: Revelações, Subversões, Superações. Campinas, SP: Alínea, 2007. p. 217 - 230.

FREITAS, M. T. A. A abordagem sócio-histórica como orientadora da pesquisa qualitativa. Cadernos de Pesquisa, São Paulo, n.116, p. 21-39, jul. 2002. Disponível em: http://www.scielo.br/scielo.php?script=sci_arttext\&pid=S0100-15742002000200002. Acesso em: 25 fev. 2020.

FREITAS, M. T. A. A pesquisa de abordagem histórico-cultural: um espaço educativo de construção de sujeitos. Teias, Rio de Janeiro, v. 10, n. 19, p. 1-12. 2009. Disponível em: http://www.e-publicacoes.uerj.br/index.php/revistateias/article/view/24057. Acesso em: 15 set. 2015.

GARCIA, R. L. Reflexões sobre a responsabilidade social do pesquisador. In: MOREIRA, A. F. et al. Para quem pesquisamos, para quem escrevemos: o impasse dos intelectuais. São Paulo: Cortez, 2001. p. $11-36$.

GEERTZ, C. From the native's point of view: on the nature of anthropological understanding. In: RABINOW, P.; SULLIVAN, W. Interpretive social science. Berkeley: University of California Press, 1979. p. 26-45. 
GÓES, M. C. A natureza social do desenvolvimento psicológico. Cadernos Cedes, Campinas, n. 24, p. 17-24, 1991.

JARAMILLO, D.; FREITAS, M. T. M.; NACARATO, A. M. Diversos caminhos de formação: apontando para outra cultura profissional do professor que ensina Matemática. In:

NACARATO, A. M.; LOPES, C. E. (org.). Escritas e leituras na Educação Matemática. Belo Horizonte: Autêntica, 2009. p. 163 - 190.

MARQUES, M. O. Escrever é preciso: o princípio da pesquisa. 2.ed. Ijuí: Unijuí, 2011.

MOLON, S. I. Questões metodológicas de pesquisa na abordagem sócio-histórica. Revista Informática na educação: teoria \& prática, Porto Alegre, v. 11, n. 1, p. 56 - 68. jan./jun. 2008. Disponível em: http://www.seer.ufrgs.br/InfEducTeoriaPratica/article/viewFile/7132/4884. Acesso em: 22 jan. 2016.

MORAES, R. A educação de professores de ciências: uma investigação da trajetória de profissionalização de bons professores. 1991. Tese (Doutorado em Educação) - Faculdade de Educação, Universidade Federal do Rio Grande do Sul, Porto Alegre, 1991.

MORAES, R. Uma tempestade de luz: a compreensão possibilitada pela análise textual discursiva. Ciência \& Educação, Bauru, v. 9, n. 2, p. 191-211, out. 2003. Disponível em: https://www.scielo.br/pdf/ciedu/v9n2/04.pdf. Acesso em: 24 set. 2020.

MORAES, R.; GALIAZZI, M. do C. Análise textual discursiva. 2.ed. Ijuí: Unijuí, 2011.

MORAES, R.; GALIAZZI, Maria do Carmo. Análise Textual Discursiva. 3. ed. Ijuí: Unijuí, 2016.

PRADO, G.; SOLIGO, R. Porque escrever é fazer história: revelações, subversões, superações. Campinas: Alínea, 2007.

RODRIGUES, A. Tornar-se professor de Psicologia: encontros com o outro. 2011. Tese (Doutorado em Educação) - Universidade Federal de Pelotas, Pelotas, 2011.

SARMENTO, D. F. A Teoria Histórico-Cultural de L. S. Vygotsky: uma análise da produção acadêmica e científica no período de 1986 a 2001. 2006. Tese (Doutorado em Educação) Universidade Federal do Rio Grande do Sul, Porto Alegre, 2006.

STAKE, R. Pesquisa qualitativa: estudando como as coisas funcionam. Porto Alegre: Artmed, 2011.

TARDIF, M. Saberes docentes e formação profissional. 17.ed. Petrópolis: Vozes, 2014.

TAYLOR, S.; BOGDAN, R. Introducción a los métodos cualitativos de investigación: La búsqueda de significados. Buenos Aires: Paidós, 1984.

VIGOTSKI, L. S. A formação social da mente: o desenvolvimento dos processos psicológicos superiores. Trad. José Cipolla Neto; Luís Silveira Menna Barreto; Solange Castro Afeche. 7.ed. São Paulo: Martins Fontes, 2007.

Recebido em: 24 de outubro de 2020.

Aceito em: 12 de novembro de 2020. 